\title{
Gustavo Arcenegui Parreño (1948-2018): Un auténtico promotor de la seguridad en la construcción
}

DOI: 10.12961/aprl.2018.21.02.6

El 25 de enero de 2018 nos dejó Gustavo Arcenegui. Era Ingeniero Agrónomo y Arquitecto Técnico. Recibió el Premio Nacional por su Proyecto Fin de Carrera "Manual para la redacción de estudios básicos de seguridad y salud laboral en las obras de edificación”. Contaba con la especialización superior en Prevención de Riesgos Laborales. Desde el año 1983 hasta el año 2014 fue Director del Centro Territorial de Seguridad y Salud en el Trabajo de Alicante. Este centro era la continuación del antiguo Gabinete de Seguridad e Higiene en el Trabajo y en la actualidad pertenece al INVASSAT (Instituto Valencianos de Seguridad y Salud en el Trabajo) de la Generalitat Valenciana.

Desde este Centro desarrolló una gran actividad profesional en el campo de la Seguridad en la Construcción. Participó en actividades de Normalización de AENOR, desempeñando diferentes cargos de Secretario y Coordinador en diversos grupos de trabajo sobre Protección Colectiva, Sistemas Provisionales de Protección de Borde, Protección de Terminaciones de Armaduras de Acero en Obra, Redes de Seguridad en huecos pequeños, Equipamientos para Trabajos temporales en Obra, Andamios y Plataformas de carga y descarga.

Fue asimismo profesor asociado de la asignatura de Seguridad y Prevención del Departamento de Construcciones Arquitectónicas de la Universidad de Alicante. Y también desarrolló tareas docentes en los Master de Seguridad e Higiene de la Construcción Tanto en la Universidad de Alicante como en la Universidad Politécnica de Valencia.

A lo largo de su carrera recibió múltiples premios destacando el premio Nacional de Seguridad en la Construcción 2001, y el Premio Caupolican, año 1996, de la Arquitectura Técnica a la SSL, accésit al trabajo "Las redes de Seguridad contra las caídas de Personas de Altura en el Sector de la Construcción”.

Fruto de esta amplia actividad se convirtió en referente y cualificado experto en temas de Seguridad Laboral en la Construcción como lo refleja su participación, junto a otros autores, en el libro "Redes de Seguridad en la Construcción" y como coautor, en colaboración con Lucía Bartolomé, del libro "Seguridad y Prevención”.

Pero además de ser un gran profesional, fue una persona de profundas convicciones morales y sociales, que guiaban todas sus actuaciones. Amante de la vida sana y del deporte, que practicaba con sus colegas y amigos como Temístocles Quintanilla, Pepe
Saiz y Manolo Gil. En lo personal era de natural tímido, sobre todo cara a las actuaciones en público, pero con la experiencia que adquirió a través de sus múltiples actividades de conferenciante y docente, fue dominando esta faceta y llegó a ser un muy buen comunicador. Los que trabajábamos con él, siempre recordaremos con una sonrisa las reuniones navideñas para darnos su felicitación personal, que dada su timidez, batían récords de velocidad y de brevedad. Ahora llevaba un año jubilado disfrutando de su familia y de sus nietos y solía reunirse periódicamente a desayunar con sus antiguos compañeros convocándonos a través de Mariem Gomis y de María Luisa López sus fieles colaboradoras.

Y así es el recuerdo y el ejemplo que nos deja Gustavo de persona trabajadora, recta y honesta como pocas.

En nombre de todos los compañeros que tuvimos la suerte de trabajar con Gustavo Arcenegui,

José María Roel Valdés

Médico del Trabajo. INVASSAT, Alicante.

José Saiz Nuñez

Técnico Superior en Prevención de Riesgos Laborales, INVASSAT, Alicante. 